Supporting Information

\title{
What Structural Features Make Porous Carbons Work for Redox- Enhanced Electrochemical Capacitors? A Fundamental Investigation
}

Yang Zhao ${ }^{\dagger, \ddagger}$, Erin E. Taylor ${ }^{\sharp}$, Xudong Hu ${ }^{\ddagger}$, Brian Evanko", Xiaojun Zeng ${ }^{\ddagger}$, Hengbin Wang ${ }^{\nabla}$, Ryohji Ohnishi ${ }^{\circ}$, Takaki Tsukazaki ${ }^{\star}$, Jian-Feng Li*,†, Nicholas P. Stadie\#, Seung Joon Yoo*, Galen D. Stucky ${ }^{\sharp}, \|$, Shannon W. Boettcher*,

$\uparrow$ State Key Laboratory of Physical Chemistry of Solid Surfaces, Collaborative Innovation Center of Chemistry for Energy Materials (iChEM), College of Chemistry and Chemical Engineering, Xiamen University, Xiamen 361005, P. R. China

\$ Department of Chemistry and Biochemistry, University of California Santa Barbara, Santa Barbara, California 93106, United States

$\S$ Department of Chemistry and Biochemistry, the Materials Science Institute, and the Oregon Center for Electrochemistry, University of Oregon, Eugene, OR 97403, United States

|| Materials Department, University of California Santa Barbara, Santa Barbara, California 93106, United States

$\perp$ School of Materials Science and Engineering, Gwangju Institute of Science and Technology, Gwangju 61005, Republic of Korea

\# Department of Chemistry \& Biochemistry, Montana State University, Bozeman, Montana 59717, United States

$\nabla$ Mitsubishi Chemical Center for Advanced Materials, University of California, Santa Barbara, Santa Barbara, California 93106, United States

- Science \& Innovation Center, Mitsubishi Chemical Corporation, Yokohama 227-8502, Japan

-R\&D Center, Kansai Coke and Chemicals Co., Ltd, Amagasaki 660-0095, Japan

\section{Corresponding author:}

*Email: swb@uoregon.edu; sjoonyoo@gist.ac.kr; 1 l@ 


\section{Experimental details}

Materials. All reagents and starting materials were obtained commercially and used as received without any further purification.

Potassium iodide (KI) was purchased from Merck KGaA. Polytetrafluoroethylene (60 weight \% aqueous dispersion) and perchloric acid $\left(\mathrm{HClO}_{4}, 70 \%\right)$ were purchased from Sigma-Aldrich. Potassium sulfate $\left(\mathrm{K}_{2} \mathrm{SO}_{4}\right)$, nitric acid $\left(\mathrm{HNO}_{3}\right)$, and isopropanol were purchased from VWR. Water was from a Milli-Q Simplicity ${ }^{\mathrm{TM}} 185$ system with resistivity $\geq 18.2 \mathrm{M} \Omega \cdot \mathrm{cm}$ (if not specified, all solutions in the following paragraphs refer to aqueous solutions).

Activated carbons. Microporous activated carbon MAXSORB ${ }^{\circledR}$ including MSC30 and MSP20 were produced by Kansai Coke and Chemicals and supplied by Mitsubishi Chemical. Norit ${ }^{\circledR}$ ASupra was purchased from Acros Organics. Mesoporous carbons, including Cnovel10 and Cnovel30, were purchased from Toyo Tanso USA. Additional details, including composition and pore size distribution, are reported in the manuscript.

Zeolite templated carbon (ZTC). ZTC was synthesized by a two-step procedure, ${ }^{1,2}$ as reported elsewhere. ${ }^{3}$ The zeolite NaY template (HSZ 320NAA, Tosoh Corp.) was degassed in a Büchi glass oven at $300{ }^{\circ} \mathrm{C}$ for $24 \mathrm{~h}$ under oil-free vacuum $\left(<2 \times 10^{-3} \mathrm{mbar}\right)$. The dried zeolite $(2 \mathrm{~g})$ was then transferred (under Ar) into a two-neck round-bottom flask. The dried zeolite was combined with $20 \mathrm{~mL}$ of furfuryl alcohol (FA, 99\%, Aldrich) via syringe and the mixture was stirred at room temperature, under passive vacuum for $24 \mathrm{~h}$. The impregnated solid was collected by vacuum filtration in air, washed three times with $10 \mathrm{~mL}$ aliquots of mesitylene (97\%, Aldrich), and then dried under suction on the filter frit for 15 minutes. The impregnated and rinsed zeolite was placed in an alumina boat $(10 \times 30 \times 107 \mathrm{~mm})$ which was inserted into a quartz tube $(\varnothing 45 \mathrm{~mm})$ installed in a horizontal tube furnace (HST 12/600, Carbolite Gero). The tube was purged under dry argon flow $(200 \mathrm{sccm})$ at ambient pressure. The FA within the zeolite pores was first polymerized by heating up to $80^{\circ} \mathrm{C}$ via a $10 \mathrm{~min}$ ramp and held for $24 \mathrm{~h}$. The poly-FA was then carbonized by heating up to $700{ }^{\circ} \mathrm{C}$ via a $2 \mathrm{~h}$ ramp and held for $30 \mathrm{~min}$. Further carbon impregnation was accomplished via propylene CVD at $700{ }^{\circ} \mathrm{C}$ for $5 \mathrm{~h}$; the gas flow was switched to $7 \mathrm{~mol} \%$ propylene in argon (99.99\% propylene in $99.999 \%$ argon) at $200 \mathrm{sccm}$. An annealing step (under pure argon flow) was performed by heating the zeolite-carbon composite up to $900{ }^{\circ} \mathrm{C}$ via a 40 min ramp and held for an additional $1 \mathrm{~h}$. The system was then cooled overnight, the gas flow was stopped, and the annealed zeolite-carbon composite was collected. Removal of the zeolite templated was accomplished by three sequential dissolutions in $35 \mathrm{~mL}$ of aqueous hydrofluoric acid (HF, 48-51\%, ACROS Organics). The final ZTC product was collected by centrifugation, washed three times with $35 \mathrm{~mL}$ aliquots of distilled water, and then dried in air at $40^{\circ} \mathrm{C}$.

Physical Characterizations. The porous carbon particles were characterized using scanning electron microscopy (SEM, FEI Nova Nano 650 FEG) and X-ray photoelectron spectroscopy (XPS, Kratos Axis Ultra DLD XPS equipped with a nonmonochromated Mg X-ray anode and a monochromated Al anode). The physisorption isotherms were measured with a pore analyzer (3Flex Pore Analyzer, Micromeritics Instrument Corp.) using $\mathrm{N}_{2}$. Before the sorption tests, all carbons were heated at $100{ }^{\circ} \mathrm{C}$ overnight. For mesopore distribution measurement, samples were 
degassed at $200^{\circ} \mathrm{C}$ for $6 \mathrm{~h}$, and for micro-pore distribution measurement, samples were set up with in-situ degas at $200^{\circ} \mathrm{C}$ for $6 \mathrm{~h}$ with a ramping rate of $10^{\circ} \mathrm{C} \mathrm{min}^{-1}$. The surface areas were calculated using the Brunauer-Emmett-Teller (BET) method, micropore size and mesopore size distributions were determined by nonlocalized density functional theory (NLDFT) calculations with a carbon slit-pore model. Mesopore size distributions for Cnovel10 and Cnovel30 were also obtained by the Barrett-Joyner-Halenda (BJH) method to compare (Figure S3). Quantitative measurements of iodine in digestion solutions were made with an inductively-coupled-plasma (ICP, iCAP 6300 model) atomic-emission spectrometer. Skeletal volume numbers of carbon electrodes were measured with a He pycnometer (Micromeritics AccuPyc 1340).

\section{Fabrication of redox-enhanced electrochemical capacitors (redox ECs)}

Carbon electrodes. $600 \mathrm{mg}$ of activated carbon, $35.3 \mathrm{mg}$ of acetylene black conductive additive (Vulcan ${ }^{\circledR}$ XC72R), and 4-8 mL isopropanol were combined and magnetically mixed in a $20 \mathrm{~mL}$ mixing cup at $1000 \mathrm{rpm}$ for $2 \mathrm{~min}$ followed by $2 \mathrm{~min}$ ultrasonication. Next, $117.6 \mathrm{mg}$ of polytetrafluoroethylene (PTFE) binder (60 wt. \% aqueous dispersion) was added dropwise to the resulting slurry under magnetic stirring and the mixing steps were repeated. The resulting material was rolled with a PTFE rolling pin and folded over itself 5-10 times until a single freestanding film was formed. This film was dried overnight at $130^{\circ} \mathrm{C}$ in high vacuum, ground into a powder through a mesh sieve, and then dried again under a high vacuum at room temperature. The resulting electrode material contained activated carbon, carbon black conductive additive, and PTFE binder in an 85:5:10 mass ratio, respectively. Freestanding $6 \mathrm{mg}$ (positive electrodes) or $30 \mathrm{mg}$ (negative electrodes, made of MSP20 only) electrode pellets were pressed from the powder in a $1 \mathrm{~cm}$ die (MTI Corporation) on a Carver hydraulic press under an applied uniaxial force of 2 tons, applied three times. Electrodes were $1 \mathrm{~cm}$ in diameter with areal mass loading of $7.6 \mathrm{mg} / \mathrm{cm}^{2}$ for positive electrodes and $38.2 \mathrm{mg} / \mathrm{cm}^{2}$ for the negative electrode. Thickness is listed in Table S2.

Assembly of two- and three-electrode cell. The construction of the redox-enhanced electrochemical capacitor cell with two or three electrodes is described in detail in a previous report. ${ }^{4}$ Briefly, for the preparation of each cell stack, two electrodes were soaked in $1.5 \mathrm{~mL}$ of electrolyte in a glass cup, vacuum and $\mathrm{N}_{2}(100 \mathrm{psi})$ were alternately applied for 5 min intervals, 3 times to infiltrate the hydrophobic carbon electrodes with an aqueous electrolyte. Electrodes were removed from the infiltration electrolyte cell and then gently wiped to remove excess electrolyte on the surface before cell assembly.

A two-electrode cell was built from a perfluoroalkoxy (PFA) Swagelok fitting with 12-mmdiameter stainless steel rods (McMaster-Carr). Infiltrated electrodes (in $0.4 \mathrm{M}$ or $2 \mathrm{M} \mathrm{KI}$ ) were placed on either side of an electrolyte-wetted ( $55 \mu \mathrm{L} 0.4 \mathrm{M}$ or $2 \mathrm{M} \mathrm{KI}), 12$-mm-diameter glass fiber filter separator (Whatman ${ }^{\mathrm{TM}}$ ). Thereafter, the cell stack was pressed between the two current collectors (stainless steel rods) inside the cell body.

For the three-electrode configuration tests mentioned in the manuscript, in the sections redox capacity and high-rate performance and self-discharge, the positive electrode and negative electrode were both infiltrated in $0.35 \mathrm{M} \mathrm{K}_{2} \mathrm{SO}_{4}$ electrolyte. A T-shaped Swagelok PFA union was used with an $\mathrm{Ag} / \mathrm{AgCl}$ reference electrode (Fisher Scientific ${ }^{\mathrm{TM}} \mathrm{accument}^{\mathrm{TM}}$ ) placed with the tip at 
the edge of the separator. To avoid uncontrolled diffusion of $\mathrm{I}_{2} / \mathrm{I}_{3}{ }^{-}$to excess electrolyte domain, a Nafion ${ }^{\mathrm{TM}} 212$ membrane (Fuel Cell Stores) and a wetted paper separator (Whatman \#1, wetted with $0.35 \mathrm{M} \mathrm{K}_{2} \mathrm{SO}_{4}$,) were placed between glass fiber filter (wetted with $55 \mu \mathrm{L} 3 \mathrm{M} \mathrm{KI}$ ) and a negative electrode to facilitate the comparison among various carbons at the local environment of positive electrodes. The paper separator was fashioned in a particular shape, as shown in Figure S8, such that the tip of the reference electrode could effectively make ionic contact to the electrolyte solution held in the separator.

For the three-electrode configuration in the quantification of redox species location section, a T-shaped Swagelok PFA union was used, which was flooded with $0.5 \mathrm{~mL}$ of excess electrolyte ( $0.4 \mathrm{M}$ or $2 \mathrm{M} \mathrm{KI}$ ), in which an $\mathrm{Ag} / \mathrm{AgCl}$ reference electrode (Fisher Scientific ${ }^{\mathrm{TM}}$ Accument $^{\mathrm{TM}}, 4$ $\mathrm{M} \mathrm{KCl)} \mathrm{tip} \mathrm{was} \mathrm{placed.} \mathrm{All} \mathrm{the} \mathrm{other} \mathrm{conditions,} \mathrm{including} \mathrm{the} \mathrm{electrodes,} \mathrm{electrolytes,} \mathrm{and}$ treatment, were the same as the two-electrode configuration.

Digestion of carbon electrodes and separators. Infiltrated electrodes were removed from an electrolyte infiltrated cell and then gently wiped to remove excess electrolyte on the surface and labelled "as-prepared electrodes". Electrodes from cells that were disassembled at the fullycharged state were named "fully-charged electrodes". Digestion of carbon electrodes was carried out using reported procedures with minor modifications. ${ }^{5}$ Three-five pieces of carbon electrodes $(6-30 \mathrm{mg})$ were placed in a quartz $125-\mathrm{ml}$ flask and $5 \mathrm{~mL}$ of fuming nitric acid was added. The capped flask was left overnight as a pre-oxidizing procedure. Then $15 \mathrm{~mL}$ of perchloric acid was added. The flask was assembled with a reflux condenser for cooling. The assembly was placed on a hot plate and secured by clamping to a support stand. The hot-plate temperature-control was set to $140-150{ }^{\circ} \mathrm{C}$ and the fume-cupboard safety shield was lowered. After the first hour, the temperature was increased to $180-190{ }^{\circ} \mathrm{C}$. The dissolution proceeded to completion in 6-10 $\mathrm{h}$. When the carbon electrodes were entirely dissolved, as indicated by a clear solution and only small pieces of white PTFE binder remaining (as shown in Figure S11) the heat was turned off and the solution allowed to cool. After diluting with water, the solution in the flask was used for further ICP-AES measurement to quantify iodine.

Digestion of glassy fiber separators was carried out at room temperature in 5\% hydrofluoric acid in the fume hood. The dissolution is finished within $30 \mathrm{~s}$ after placing separators into the flask containing the acid. Then the solution was diluted with water and ready for further ICP-AES measurement.

Electrochemical characterization of redox ECs. All galvanostatic charge/discharge (GCD) cycling and cyclic voltammetry (CV) tests were performed on a Bio-logic VMP3 potentiostat/galvanostat at a temperature of $25{ }^{\circ} \mathrm{C}$. Cyclic voltammetry were performed in the potential range of -0.6 to $0.8 \mathrm{~V}$ vs. $\mathrm{Ag} / \mathrm{AgCl}$ with a scan rate of $5 \mathrm{mV} / \mathrm{s}$. The applied current, $I$, for GCD testing was normalized to the dry mass (activated carbon, carbon black and PTFE binder) of the positive electrode (denoted as $\mathrm{A} / \mathrm{g}_{\mathrm{dry}}$ ) - e.g., a current of $\pm 6 \mathrm{~mA}$ was applied to cycle a cell with $6 \mathrm{mg}$ electrode at the rate of $1 \mathrm{~A} / \mathrm{g}_{\text {dry }}$. Voltage, $V$, is measured as a function of time, $t$, and charging or discharging stops when $V$ reaches $V_{\max }\left(\right.$ i.e., $1.25 \mathrm{~V} / 1.4 \mathrm{~V}$ ) for charging or $V_{\max }$ (i.e., $0 \mathrm{~V}$ ) for discharging, respectively. The following equations are used for calculating device performance: 


$$
\begin{array}{ll}
\text { Charge capacity, } Q_{c h}(\mathrm{~mA} \cdot \mathrm{h}) & Q_{c h}=I_{c h} \cdot t_{c h} \\
\text { Discharge capacity, } Q_{d i s}(\mathrm{~mA} \cdot \mathrm{h}) & Q_{d i s}=I_{d i s} \cdot t_{d i s} \\
\text { Coulombic efficiency, } \eta_{c} & \eta_{C}=Q_{d i s} / Q_{c h}
\end{array}
$$

The GCD procedure was modified for three-electrode rate tests and self-discharge tests as follows: Rate tests for various carbons were performed by charging the three-electrode cell to $(0.5 \mathrm{~V}+i R)$ at $20 \mathrm{~A} / \mathrm{g}_{\text {dry }}, 10 \mathrm{~A} / \mathrm{g}_{\text {dry }}, 5 \mathrm{~A} / \mathrm{g}_{\text {dry }}, 2 \mathrm{~A} / \mathrm{g}_{\text {dry }}, 1 \mathrm{~A} / \mathrm{g}_{\text {dry }}$, respectively, and discharging it to $(0 \mathrm{~V}-i R)$ for 20 cycles, each at the same rate as charging. Since $i R$ drop is inevitable in GCD tests, the $i R$ drop was determined between the charge and discharge step at the first cycle and voltage was corrected accordingly for each carbon sample for more accurate comparison. The self-discharge rate was studied based on the decay of discharge capacity as a function of open-circuit time, $\delta$. First, the cell was charged to $1 \mathrm{~mA} \cdot \mathrm{h}$ by applying a constant current $\left(1 \mathrm{~A} / \mathrm{g}_{\mathrm{dry}}\right)$. Then, while monitoring the cell potential decay, the cell was left at an open circuit for $6 \mathrm{~h}$. After the open circuit period, the cell was discharged to $0 \mathrm{~V}$ by extracting the same constant specific current $\left(1 \mathrm{~A} / \mathrm{g}_{\text {dry }}\right)$. Capacity retention $\eta_{R}$ is defined and calculated by the following formula:

$$
\eta_{R}=C_{d i s}(\delta) / C_{c h}(0)
$$

Note S1. Calculation of the void-space volume in carbon electrodes. The helium pycnometer works by measuring the amount of displaced gas. During the measurement, gas molecules rapidly fill the tiniest pores of the sample, only the truly solid phase of the sample displaces the gas unless the sample has inaccessible, closed pores.

First, $V_{t}$, the "true" volume (skeletal volume) of a porous carbon electrode pellet is measured by the helium pycnometer. Considering that the pycnometer measurements with enhanced precision and accuracy are made when the sample cup is near full, 15-20 electrode pellets were stacked to fill the sample cup with a volume of about $1 \mathrm{~cm}^{3}$, after being weighed on a balance.

Norit carbon is taken as an example here to show the calculation of void space for a carbon electrode:

20 carbon pellets made of activated carbon Norit has a total mass of $117.21 \mathrm{mg}$ and skeletal volume $\left(V_{t}\right)$ of $0.052 \mathrm{~cm}^{3}$. The average thickness of the pellets is $133 \pm 5 \mu \mathrm{m}$ with a diameter of $1 \mathrm{~cm}$ and a mass of $5.86 \mathrm{mg}$.

Next, $V_{s a}$, the specific apparent volume (bulk volume of carbon pellets) can be calculated by using Equation (S1)

$$
V_{s a}=\frac{1}{4} \frac{\pi d^{2} h}{m}=\frac{1}{4} \frac{3.1416 \times(1 \mathrm{~cm})^{2} \times 133 \mu \mathrm{m}}{5.86 \mathrm{mg}}=1.78 \mathrm{~cm}^{3} / \mathrm{g}
$$

The specific skeletal volume can be calculated by using Equation (S2)

$$
V_{s t}=\frac{V_{t}}{m}=\frac{0.052 \mathrm{~cm}^{3}}{117.21 \mathrm{mg}}=0.44 \mathrm{~cm}^{3} / \mathrm{g}
$$


The micro- and meso-pore volume $V_{s m}$ is estimated from desorption of $\mathrm{N}_{2}$ at $\mathrm{P} / \mathrm{P}_{0}=0.99$, which is $1.015 \mathrm{~cm}^{3} / \mathrm{g}$ for Norit carbon, hence $0.86 \mathrm{~cm}^{3} / \mathrm{g}$ for Norit carbon pellet with $85 \%$ Norit carbon.

Then the specific void space volume of Norit carbon pellet can be calculated as follows:

$V_{s v}=V_{s a}-V_{s t}-V_{s m}=1.78 \mathrm{~cm}^{3} / \mathrm{g}-0.44 \mathrm{~cm}^{3} / \mathrm{g}-0.86 \mathrm{~cm}^{3} / \mathrm{g}=0.48 \mathrm{~cm}^{3} / \mathrm{g}$

The average thickness and final void space volume for every carbon electrode are listed in Table S2.

Note S2. Estimation of double layer capacity contribution for various carbon electrodes. All CV curves for various carbon electrodes are shown in Figure S5. From the CV results, $Q_{d l}$, the double-layer specific capacity $(\mathrm{mA} \cdot \mathrm{h} / \mathrm{g})$ contributing in GCD can be estimated as follows:

$$
Q_{d l}=\frac{\int I d V \times \Delta V_{2}}{\left(2 \times v \times m \times \Delta V_{l}\right)}
$$

Where $v$ is the scan rate $(\mathrm{mV} / \mathrm{s}), m$ is the dry mass of positive electrode $(\mathrm{mg}), \Delta V_{l}$ is the potential window $(\mathrm{V})$ where no faradaic reactions are present in the voltammograms and $\int I d V$ represents the area $(\mathrm{mA} \cdot \mathrm{V})$ under the $\mathrm{CV}$ curve within $\Delta V_{1} . \Delta V_{2}$ is the electrode potential of the positive electrode charged, which is set at $0.5 \mathrm{~V}$ vs $\mathrm{Ag} / \mathrm{AgCl}$ for every carbon electrode. Norit carbon is taken as an example here to show the calculation of double-layer capacity for a carbon electrode:

$$
Q_{d l}=\frac{1.86 \mathrm{~mA} \cdot \mathrm{V} \times 0.5 \mathrm{~V}}{2 \times 5 \mathrm{mv} / \mathrm{s} \times 5.86 \mathrm{mg} \times 0.2 \mathrm{~V}}=22 \mathrm{~mA} \cdot \mathrm{h} / \mathrm{g}
$$

(i.e., the integrated area under $\mathrm{CV}$ curve of Norit carbon between $-0.5 \mathrm{~V}$ to $-0.3 \mathrm{~V}$ is $1.86 \mathrm{~mA} \cdot \mathrm{V}$, and $\Delta V_{l}$ is $0.2 \mathrm{~V}$.)

Note S3. Estimation of redox capacity contribution from a certain amount of iodide and the polyiodide concentration at the charged state of cell. We assume that the redox reaction uses $2 / 3$ of the iodide ions to provide the capacity and $1 / 3$ of the iodide ions to complex and stabilize the free iodine (Equation S3):

$$
2 \mathrm{I}^{-}+\mathrm{I}^{-} \leftrightarrow \mathrm{I}_{3}{ }^{-}+2 \mathrm{e}^{-} \quad E^{\mathrm{o}}=0.536 \mathrm{~V} \text { vs SHE }
$$

For every $1 \mathrm{~mA} \cdot \mathrm{h}$ redox capacity released, it corresponds to:

$1 \mathrm{~mA} \cdot \mathrm{h} \rightarrow 3.6 \mathrm{C} \rightarrow 2.25 \times 10^{19} \mathrm{e}^{-} \rightarrow 3.73 \times 10^{-5} \mathrm{~mol} \mathrm{e} \rightarrow 5.6 \times 10^{-5} \mathrm{~mol} \mathrm{I}^{-}$consumed

For every $3 \mathrm{~mol} \mathrm{I}^{-}$consumed, $1 \mathrm{~mol}$ of $\mathrm{I}^{-}$is formed.

The pore volumes of the $6 \mathrm{mg}$ positive electrodes, Cnovel 30 and MSC30, are estimated to be $17 \mu \mathrm{L}$ and $12.4 \mu \mathrm{L}$, respectively. The electrolyte volume in separator is roughly estimated to be $55 \mu \mathrm{L}$ as added in assembling the cell. With the contents of iodide measured from elemental 
analysis, the redox capacity and the polyiodide concentration in positive electrode and separator at the charged state of cell were estimated accordingly.

Table S1. Partial surface area accumulated from different pore size range for all carbon materials tested

\begin{tabular}{|c|c|c|c|c|c|c|c|}
\hline & Centralized & $\begin{array}{l}<1 \\
\mathrm{~nm}\end{array}$ & $1-2 \mathrm{~nm}$ & $2-3 \mathrm{~nm}$ & $3-30 \mathrm{~nm}$ & $>30 \mathrm{~nm}$ & $\begin{array}{c}\text { Specific } \\
\text { surface area }\end{array}$ \\
\hline & pore size $(\mathrm{nm})$ & & & cremen & ntal pore & area $\left(\mathrm{m}^{2}\right.$ & \\
\hline MSC30 & $<0.8$ and $1.1-3$ & 933 & 1766 & 684 & 28 & 1 & 3410 \\
\hline MSP20 & $<1.1$ & 1594 & 900 & 45 & 1 & 0 & 2540 \\
\hline Norit & $<0.8$ and $1.1-1.6$ & 900 & 872 & 192 & 18 & 2 & 1980 \\
\hline ZTC & 1.2 & 85 & 3378 & 72 & 35 & 0 & 3570 \\
\hline Cnovel10 & $5-10$ & 0 & 0 & 125 & 920 & 16 & 1061 \\
\hline Cnovel30 & $20-30$ & 0 & 0 & 26 & 415 & 30 & 471 \\
\hline
\end{tabular}

Table S2. Average thickness and void space volume of carbon electrodes made of different materials

\begin{tabular}{|c|c|c|}
\hline Carbon electrodes & Average thickness $(\boldsymbol{\mu m})$ & Void space $\left(\mathbf{c m}^{\mathbf{3}} \mathbf{g}^{-1}\right)$ \\
\hline Cnovel30 & $244.8 \pm 12.6$ & 1.35 \\
\hline Cnovel10 & $217.9 \pm 13.9$ & 0.83 \\
\hline Norit & $132.6 \pm 4.8$ & 0.55 \\
\hline MSP20 & $133.3 \pm 9.0$ & 0.45 \\
\hline MSC30 & $178.2 \pm 5.6$ & 0.67 \\
\hline ZTC & $154 \pm 5.7$ & 0.27 \\
\hline MSP20 $(30 \mathrm{mg})$ & $518.6 \pm 9.1$ & \\
\hline
\end{tabular}

Table S3. Performance metrics normalized to different cell components

\begin{tabular}{|c|c|c|c|}
\hline & & Dry mass & Wet mass \\
\hline $\begin{array}{c}\text { 0.4 M KI } \\
\text { Cnovel30 }\end{array}$ & Mass for normalization (mg) & 6 & 17.18 \\
\hline 0.4 M KI & Mass for normalization (mg) & 6 & 44 \\
MSC30 & Specific capacity (mAh/g) & 172 & 55 \\
\hline 2 M KI & Mass for normalization (mg) & 6 & 40.57 \\
MSC30 & Specific capacity (mAh/g) & 217 & 32 \\
\hline
\end{tabular}

Dry mass is assigned as a mass of positive electrode only, and the wet mass is the combination of dry mass of positive electrode and all active species, KI, in the cell, including those absorbed into the infiltrated electrodes. 

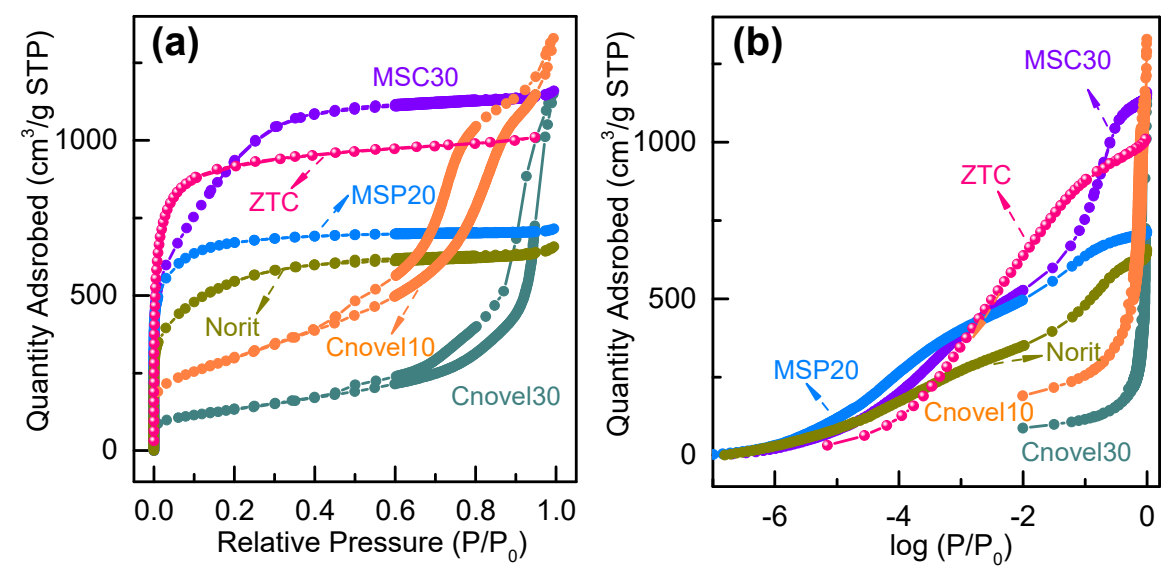

Figure S1. $\mathrm{N}_{2}$ adsorption isotherms of carbon materials at $77 \mathrm{~K}$. (a) $\mathrm{P} / \mathrm{P}_{0}$ is expressed in the linear scale and (b) logarithmic scale.

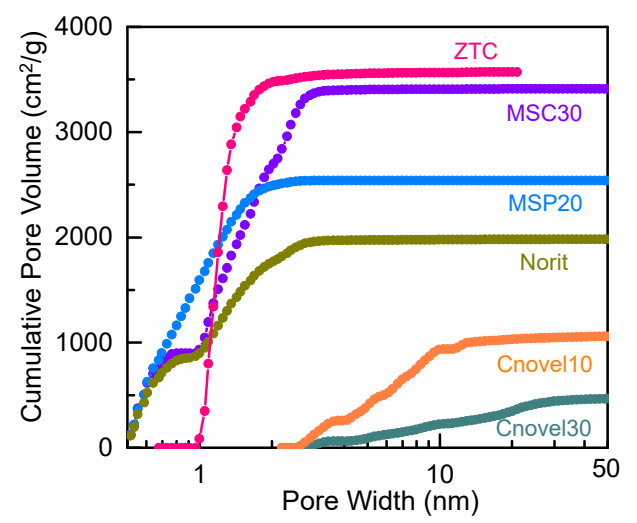

Figure S2. Cumulative pore area curves of carbon materials.

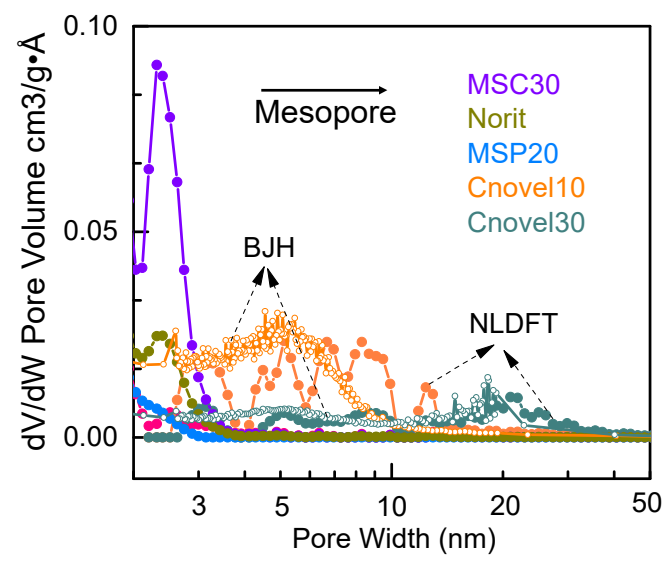

Figure S3. Pore-size distribution of carbon materials ranging from $2 \mathrm{~nm}$ to $50 \mathrm{~nm}$. Results of mesoporous carbons including Cnovel10 and Cnovel30 were obtained with both the NLDFT method and BJH method to compare. 

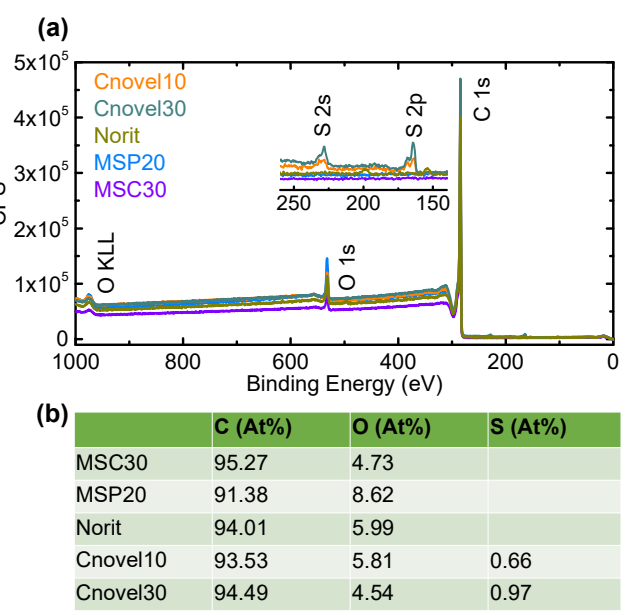

Figure S4. (a) XPS survey spectra of sample activated carbons, inserted showing the zoom-in spectra ranging from 250 to $150 \mathrm{eV}$. (b) Contents of three elements, C, O, S, for different activated carbon.
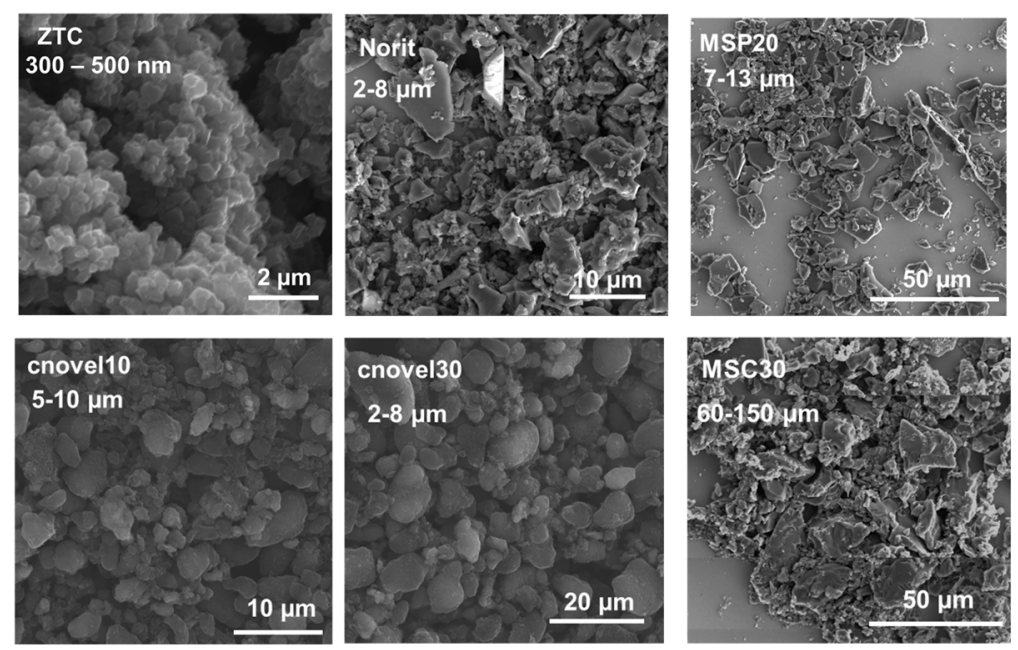

Figure S5. SEM images of pristine carbon materials labeled with particle-size distribution.
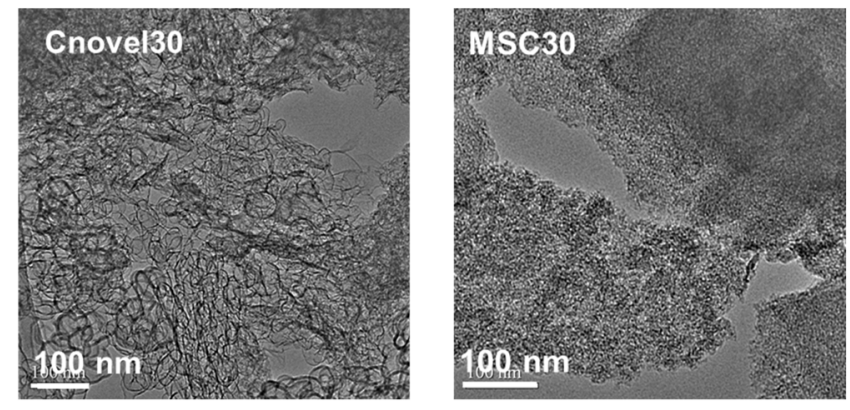

Figure S6. TEM images of mesoporous carbon Cnovel30 and microporous carbon MSC30. 

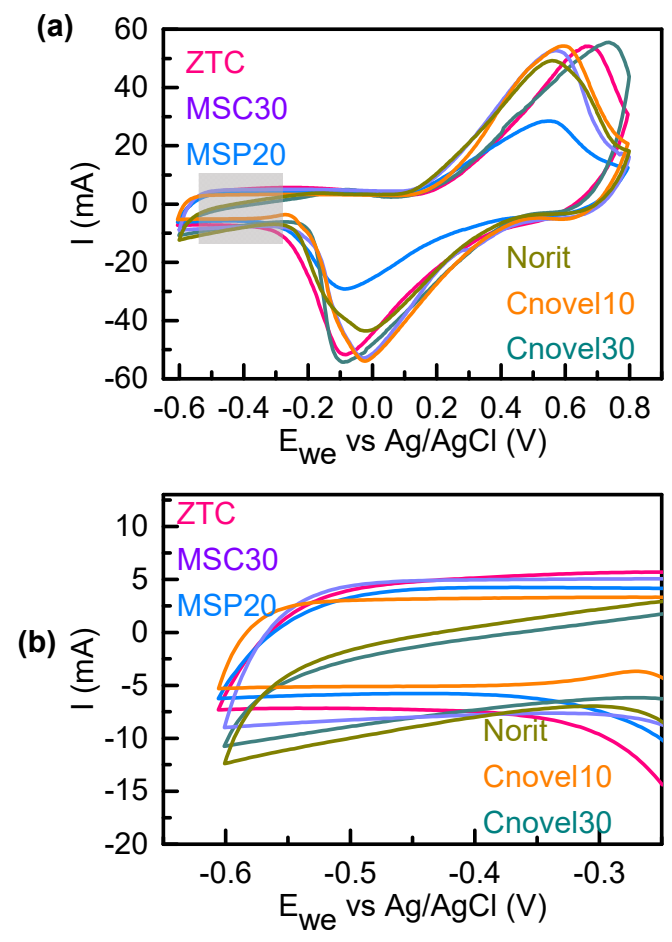

Figure S7. (a) The voltammograms collected at $5 \mathrm{mV} / \mathrm{s}$ in a three-electrode cell for all carbons. The area in the gray box was utilized to estimate capacity contributed from DL charging. (b) The gray area from (a) on expanded axes.

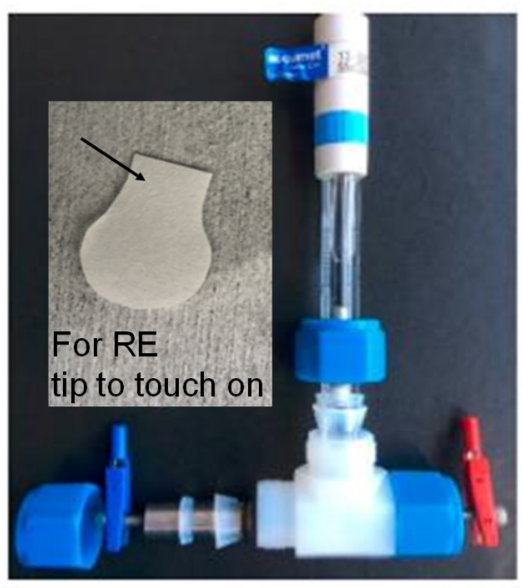

Figure S8. Threee-electrode custom Swagelok cells, with inset showing the second separator for attaching the reference electrode (RE). 


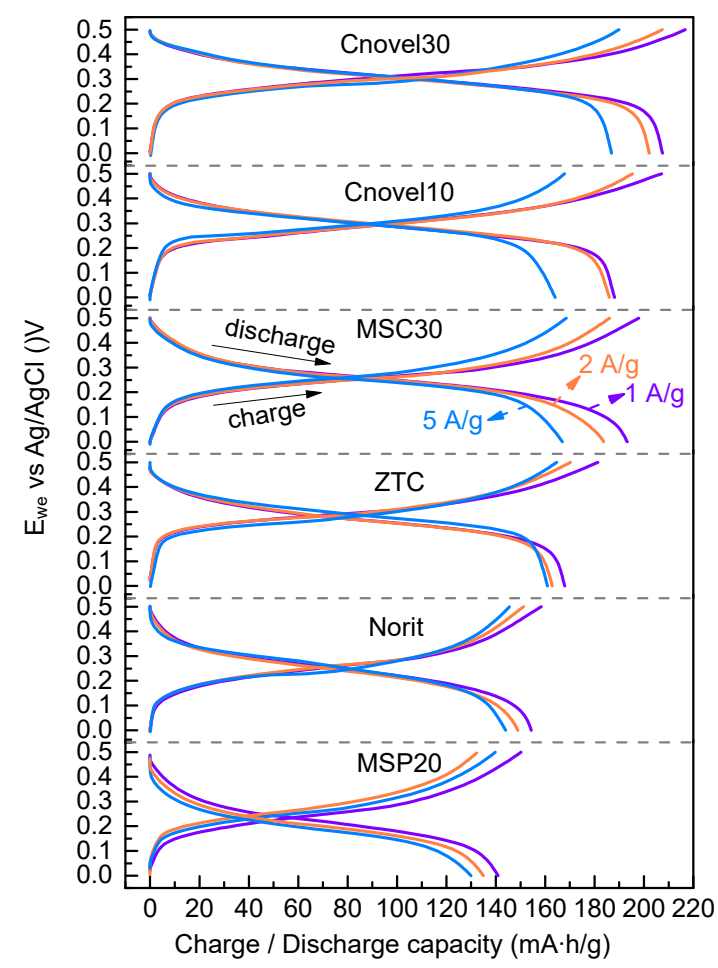

Figure S9. Galvanostatic charge / discharge curves ( $i R$ corrected) of different carbons as positive electrodes at various rates of $5 \mathrm{~A} / \mathrm{g}$ (blue), $2 \mathrm{~A} / \mathrm{g}$ (orange), and $1 \mathrm{~A} / \mathrm{g}$ (purple).

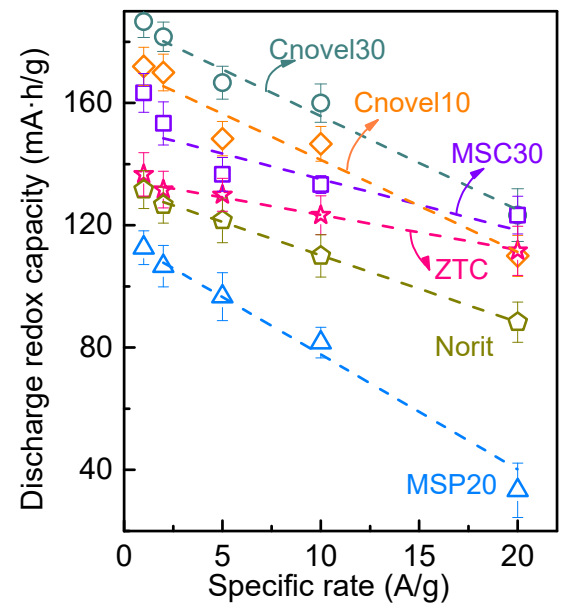

Figure S10. Redox capacity from discharge (double-layer capacitance subtracted) of different carbons as positive electrodes cycled in order at $20 \mathrm{~A} / \mathrm{g}, 10 \mathrm{~A} / \mathrm{g}, 5 \mathrm{~A} / \mathrm{g}, 2 \mathrm{~A} / \mathrm{g}$, and $1 \mathrm{~A} / \mathrm{g}$, normalized to the dry mass of positive electrode in each case. 


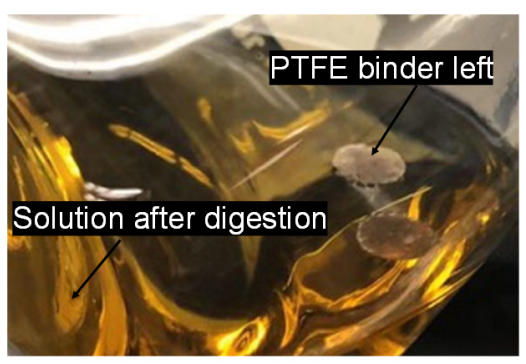

Figure S11. The residual solution after digestion of carbon electrodes.

\section{References}

(1) Matsuoka, K.; Yamagishi, Y.; Yamazaki, T.; Setoyama, N.; Tomita, A.; Kyotani, T., Extremely High Microporosity and Sharp Pore Size Distribution of a Large Surface Area Carbon Prepared in the Nanochannels of Zeolite Y. Carbon 2005, 43 (4), 876-879.

(2) Ma, Z.; Kyotani, T.; Tomita, A., Synthesis Methods for Preparing Microporous Carbons with a Structural Regularity of Zeolite Y. Carbon 2002, 40 (13), 2367-2374.

(3) Taylor, E. E.; Garman, K.; Stadie, N. P., Atomistic Structures of Zeolite-Templated Carbon. Chem. Mater. 2020, 32 (7), 2742-2752.

(4) Evanko, B.; Yoo, S. J.; Chun, S.-E.; Wang, X.; Ji, X.; Boettcher, S. W.; Stucky, G. D., Efficient Charge Storage in Dual-Redox Electrochemical Capacitors through Reversible Counterion-Induced Solid Complexation. J. Am. Chem. Soc. 2016, 138 (30), 9373-9376.

(5) Buzzelli, G.; Mosen, A. W., Perchloric Acid Dissolution of Graphite and Pyrolytic Carbon. Talanta 1977, 24 (6), 383-385. 